\title{
Association of Birthweight and Head Circumference at Birth to Cognitive Performance in 9- to 10-Year-Old Children in South India: Prospective Birth Cohort Study
}

\author{
SARGOOR R. VEENA, GHATTU V. KRISHNAVENI, ANDREW K. WILLS, ANURA V. KURPAD, SUMITHRA MUTHAYYA, \\ JACQUELINE C. HILL, SAMUEL C. KARAT, KIRAN K. NAGARAJAIAH, CAROLINE H. D. FALL,
} AND KRISHNAMACHARI SRINIVASAN

\begin{abstract}
Epidemiology Research Unit [S.R.V., G.V.K., S.C.K., K.K.N.], Holdsworth Memorial Hospital, Mysore 570021, Karnataka, India; MRC Epidemiology Resource Centre [A.K.W., J.C.H., C.H.D.F.], Southampton General Hospital, Southampton, SO166YD, United Kingdom; St. John's Research Institute [A.V.K., S.M., K.S.], St. John's National Academy of Health Sciences, Bangalore 560034, Karnataka, India
\end{abstract}

\begin{abstract}
To examine whether birthweight and head circumference at birth are associated with childhood cognitive ability in South India, cognitive function was assessed using three core tests from the Kaufman Assessment Battery for children and additional tests measuring long-term retrieval/storage, attention and concentration, and visuospatial and verbal abilities among 505 full-term born children (mean age 9.7 y). In multiple linear regression adjusted for age, sex, gestation, socioeconomic status, parent's education, maternal age, parity, body mass index, height, rural/urban residence, and time of testing, Atlantis score (learning ability/long-term storage and retrieval) rose by $0.1 \mathrm{SD}$ per SD increase in newborn weight and head circumference, respectively ( $p<0.05$ for all), and Kohs' block design score (visuospatial ability) increased by 0.1 SD per SD increase in birthweight $(p<0.05)$. The associations were reduced after further adjustment for current head circumference. There were no associations of birthweight and/or head circumference with measures of short-term memory, fluid reasoning, verbal abilities, and attention and concentration. In conclusion, higher birthweight and larger head circumference at birth are associated with better childhood cognitive ability. The effect may be specific to learning, longterm storage and retrieval, and visuospatial abilities, but this requires confirmation by further research. (Pediatr Res 67: 424-429, 2010)
\end{abstract}

$\mathrm{R}$ ecent evidence links poor fetal growth to lower "human capital" outcomes such as school achievement and adult income or assets (1). One mechanism could be suboptimal fetal brain development, leading to decreased cognitive ability in individuals with reduced intrauterine growth. A variety of adverse factors during pregnancy associated with lower birthweight could impair neurogenesis, which begins in early gestation and the processes of gliogenesis, cell migration, and dendrite formation, which occur throughout gestation $(2,3)$. Head circumference at birth has been shown to correlate with brain size (4).

Studies reporting associations between lower birthweight or head circumference at birth and poorer cognitive function in later life (childhood or adulthood) have mainly focused on

Received June 29, 2009; accepted November 17, 2009.

Correspondence: Sargoor R. Veena, M.B.B.S., Epidemiology Research Unit, Holdsworth Memorial Hospital, P.O. Box 38, Mandi Mohalla, Mysore 570021, Karnataka, India; e-mail veenasr@gmail.com

Supported by the Parthenon Trust, Switzerland, the Wellcome Trust and Medical Research Council, United Kingdom. "high-risk" individuals [born low birthweight, premature, or intrauterine growth restriction (IUGR)] $(5,6)$. However, several recent studies, including one systematic review (7), have reported associations between birthweight and cognitive functions even in children who were born at full-term and across the normal range of birthweight and/or head circumference $(8-14)$. Data from developing countries is scarce. Although it has been shown that, as in high-income countries, low birthweight and/or IUGR babies have poorer childhood cognitive ability compared with normal weight babies (15-17), no studies have assessed cognitive function across the full range of birth size. Mean birthweight in India is around $2.7 \mathrm{~kg}$, almost $800 \mathrm{~g}$ lower than among white babies in high-income countries $(18,19)$. This is thought to be mainly because of modifiable factors such as maternal stunting, dietary inadequacy, and infections (20). Evidence that small size at birth is associated with impaired cognitive development would strengthen advocacy for policies to invest in maternal health.

Studies have shown that childhood cognitive function is strongly influenced by the family's socioeconomic status (SES) $(5,7,10,12,21)$. These factors are also related to birth size and, partly, may act through fetal development but could equally influence cognitive function through genetic mechanisms or through postnatal nutrition, stimulation, growth, and development. It is important to be able to adjust for these and other confounding variables to assess the potential importance of prenatal development on cognitive ability in children.

The Mysore Parthenon Study $(19,22)$ provides an opportunity to examine associations between birth measurements and cognitive function in healthy 9- to 10-y-old children in an Indian population and control for potentially important confounders, including parental educational achievement and SES. Our objectives were to test the hypothesis that lower birthweight and smaller head circumference at birth are associated with poorer scores in tests of cognitive function, independent of socioeconomic factors.

\footnotetext{
Abbreviations: GDM, Gestational diabetes mellitus; HMH, Holdsworth Memorial Hospital; KABC, Kaufman Assessment Battery for children; SES, Socioeconomic status
} 


\section{METHODS}

Study design and participants. The Mysore Parthenon study $(19,22)$ is a prospective birth cohort study, designed to examine the incidence and determinants of gestational diabetes (GDM) and its short and long-term effects in the offspring in India. Between June 1997 and August 1998, women booking consecutively into the antenatal clinic of the Holdsworth Memorial Hospital (HMH), Mysore, were recruited for the study. HMH is a general hospital and not a specialist referral unit. It is one of three large maternity units in Mysore and is situated in a relatively poor area of the city. Women who deliver at HMH are from all socioeconomic groups, with the majority from the middle and lower middle class. Although patients pay for treatment, HMH offers concessions for the poorest and provides a niche between the free government hospitals and private nursing homes. Of 1233 recruited women satisfying the eligibility criteria (singleton pregnancy; $<32$-wk gestation determined by last menstrual period date or a first trimester ultrasound scan; and no prior history of diabetes), 830 participated (67\%) and 674 delivered at HMH (Fig. 1). Neonatal anthropometry was performed on 663 live born babies without major congenital anomalies. All the children (excluding 25 deaths and eight with major medical problem) were followed up, with repeat anthropometry, annually on the child's birthday ( $\pm 4 \mathrm{wk}$ ) till the age of $5 \mathrm{y}$ and, thereafter, every 6 mo after the birthday ( $\pm 4 \mathrm{wk}$ ). These children were invited for assessment of their cognitive function at the age of 9-10 y (September 2007-May 2008). Of the 630 children, 542 (86\%) underwent cognitive assessment, and the remaining 88 (14\%) were lost to follow-up (Fig. 1). Excluding 37 preterm children, the current analysis is restricted to 505 (239 boys and 266 girls) full-term children. The study was approved by the HMH research ethics committee, and informed verbal consent was obtained from parents and children.

Neonatal anthropometry. Neonatal birthweight and occipitofrontal head circumference were measured according to a standard protocol, within $72 \mathrm{~h}$ of birth (19). Birthweight was measured to the nearest $5 \mathrm{~g}$ using a digital weighing scale (Seca, Hamburg, Germany). Head circumference was measured in triplicate to the nearest $1 \mathrm{~mm}$, using a blank fiber-glass tape, which was marked and measured against a fixed ruler. The average of three readings was used.

Cognitive tests. The cognitive measures consisted of a series of neuropsychological tests applicable for use in school-aged children related to specific cognitive domains (memory, attention, and fluid reasoning) consistent with the Carroll model (23). The cognitive battery included three core tests from

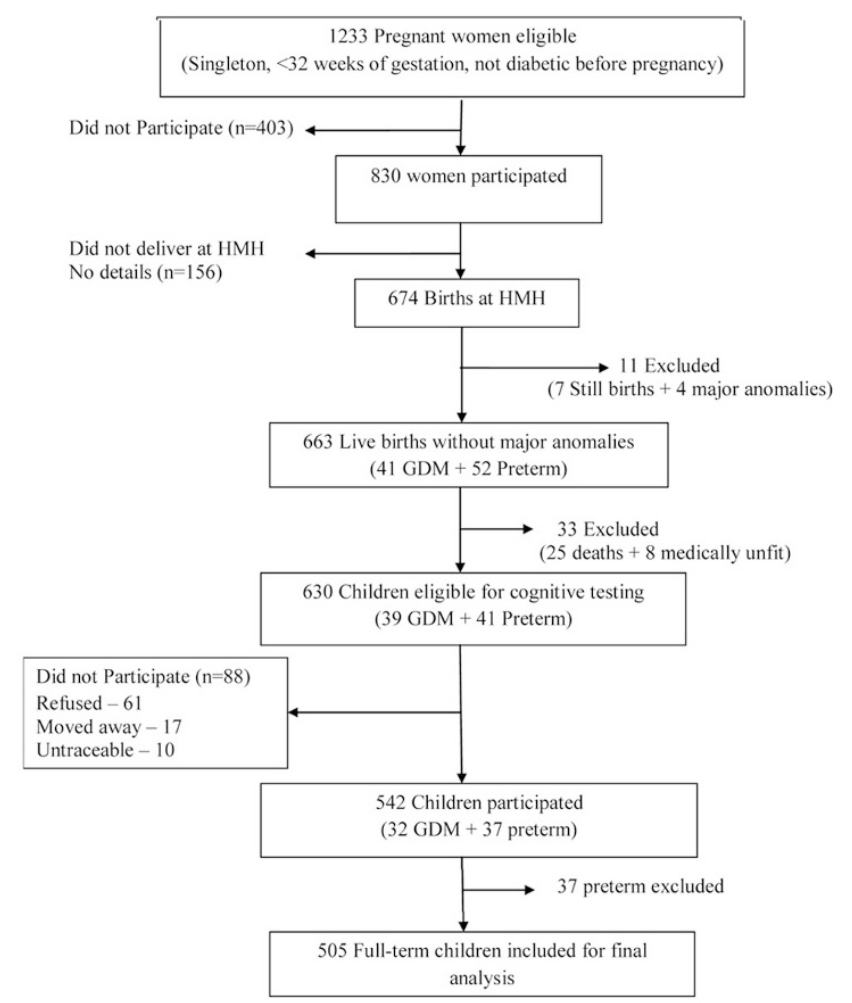

Figure 1. Flow diagram depicting the study participants. the Kaufman Assessment Battery for children-second edition, 2004 (KABCII) (24) and additional tests (25-28) that underwent an extensive adaptation process to ensure their applicability in the local cultural context. The adaptation initially included judgemental (qualitative) procedure consisting of iterations of translating, piloting, and modifying the instrument (instructions, examples, and items) based on the construct, language, culture, theory, and familiarity applicable to the local cultural context (29). This was followed by a statistical (quantitative) procedure evaluating the adequacy of the adapted version using structural equation modeling, split-half technique measuring internal consistency of cognitive domains with subtests, correlation tests for those domains without subtests, and multivariate ANOVA to test the performance of the adapted version against gender and age. Subtests showed relatively high loadings on the general cognitive factor, reliabilities, largely replicating the Cattell-Horn-Carroll model underlying the original KABC-II, and external relations with demographic characteristics such as children's age, gender, and scholastic achievement were as expected (30). The description of these cognitive tests are summarized in Table 1 and covered the domains of short-term memory, long-term memory and retrieval ability, visuospatial ability, and language production. All tests were administered to each child in a single session of 60 to $90 \mathrm{~min}$ at the epidemiology research unit, $\mathrm{HMH}$, in separate rooms free from distraction by one of the two trained masters' level child psychologists (unaware of children's birth measurements) in the local Kannada language.

Covariates. At the time of recruitment, details of maternal age, parity, and area of residence (urban or rural) were recorded. None of the mothers had ever smoked or consumed alcohol. At $30 \pm 2$-wk gestation, the women had a 100-g oral glucose tolerance test (OGTT), and detailed anthropometric measurements were measured by one of two trained observers using standardized methods as described previously (22). Season of birth [summer: March-June (average temperature maximum: $33^{\circ} \mathrm{C}$ and minimum: $21^{\circ} \mathrm{C}$ ); rainy: JulyOctober $\left(29^{\circ} \mathrm{C}\right.$ and $\left.19^{\circ} \mathrm{C}\right)$; and winter: November-February $\left(29^{\circ} \mathrm{C}\right.$ and $\left.\left.18^{\circ} \mathrm{C}\right)\right]$ were recorded at the time of birth. We also collected details of the parent's educational level in completed years and current SES using the Standard of Living Index (SLI), a standardized questionnaire designed by National Family Health Survey-2 (31). For the children's current anthropometry, data collected at the 9.5-y follow-up for 479 children and at the 9-y follow-up for the remaining 24 children were used.

Statistical methods. Variables not satisfying normality assumptions were either log transformed [maternal body mass index (BMI) and Kohs block design score] or square root transformed (pattern reasoning score). Sexspecific SD scores for birth measurements were calculated using internally generated growth charts, which were constructed using the LMS $(L=$ skewness; $M=$ median; $S=$ coefficient of variation) method (32). Scores for cognitive tests were $z$-standardized to facilitate interpretation. Comparisons of birth size, current size, and cognitive scores between boys and girls were made using $t$ test. Associations of covariates with birth measurements (exposures) and cognitive ability (outcomes) were initially assessed using multiple linear regression, adjusting for sex and current age. For categorical covariates, (parity and season at birth), the largest category was used as the reference, and tests of general association (Wald) were performed. Associations between birth measurements and cognitive function were then analyzed using multiple linear regression, adjusting for variables that were associated with either birth measurements or cognitive outcomes. A series of models were used: model 1: gestational age at birth, the children's sex, and current age; model 2: model 1 parameters plus the family's SES and parental education; model 3: model 2 parameters plus urban or rural residence, maternal age, BMI, height, parity, and time of the day when cognitive tests were administered; model 4: model 3 parameters plus child's current head circumference. Differences between the various cognitive tests in their associations with birth size were assessed by testing whether the difference in the $Z$-score for each test from the mean $Z$-score of the other tests was associated with birth size, using linear regression. Stata version 10 (Stata corporation, TX) was used for all analyses.

\section{RESULTS}

Characteristics of the study cohort are summarized in Table 2 . At birth, boys were heavier and had larger head circumference than girls. Birth measurements [mean (SD)] were similar in those who took part in the study to those who did not [birthweight $2.905(0.428) \mathrm{kg}$ versus $2.892(0.432) ; p=0.8$ and head circumference 33.9 (1.3) $\mathrm{cm}$ versus 33.7 (1.5); $p=$ $0.3]$. At the time of the study, boys were taller and had larger 
Table 1. Description of the cognitive tests used in the study

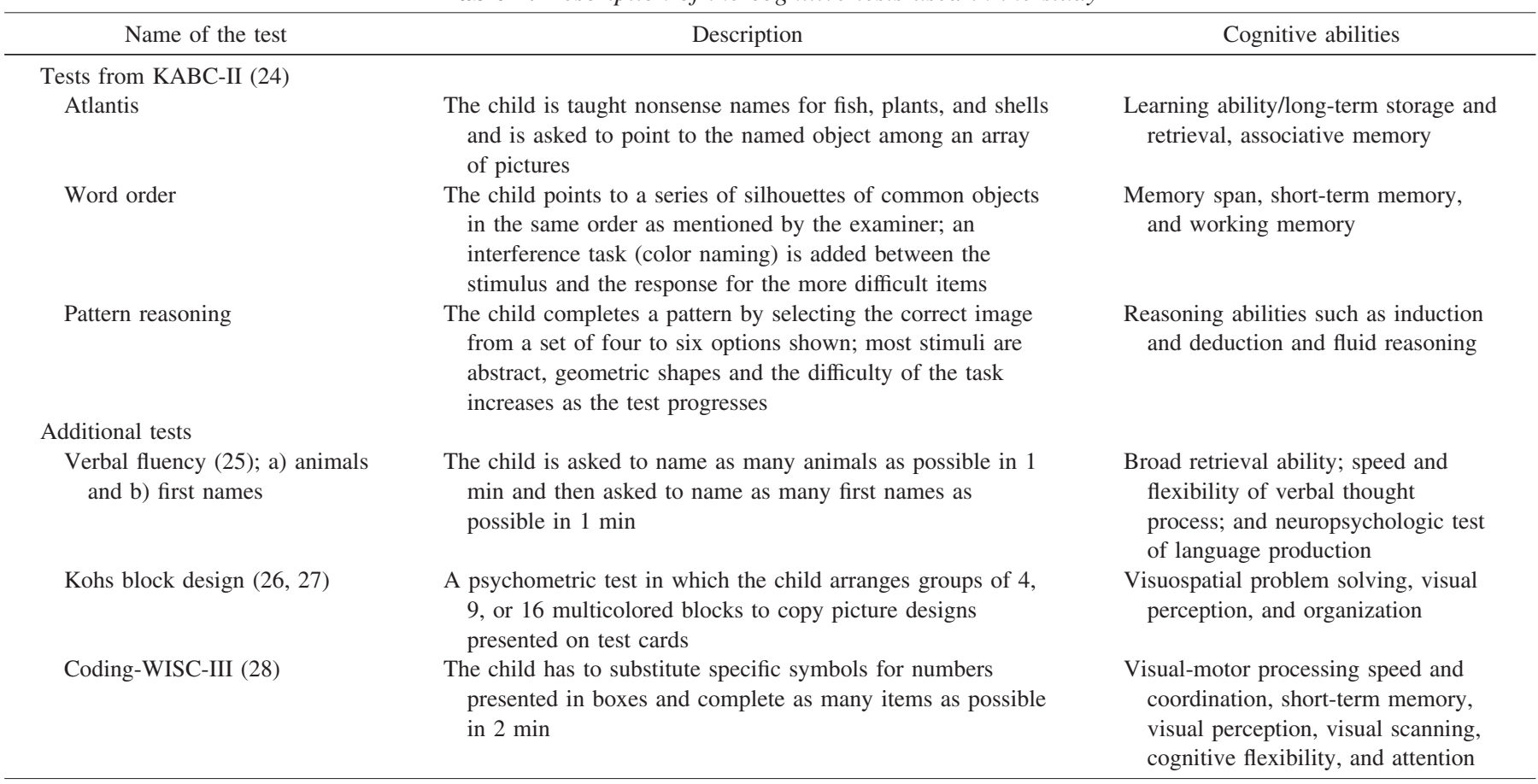

WISC-III-Wechsler intelligence scale for children-third edition.

head circumference than girls. Girls scored better than boys in tests of word order, pattern reasoning, and verbal fluencynames and coding. Correlations between the various cognitive test scores ranged from 0.2 to 0.3 .

One percent of mothers were illiterate; $\sim 34 \%$ had received only primary school education; $51 \%$ had completed secondary school education; and $14 \%$ were graduates/postgraduates/ professionals. Corresponding figures for fathers were $3 \%$, $34 \%, 40 \%$, and $23 \%$, respectively. Approximately $33 \%$ of children were born during winter, $35 \%$ during summer, and $32 \%$ during the rainy season.

Associations between confounding variables and birth measurements. Birthweight and head circumference increased with increasing gestational age, SES, parental education, maternal age, height and BMI, and parity and were higher in those whose mothers had GDM $(p<0.05$ for all; data not shown). There was no association of rural/urban residence or season of birth with birthweight and head circumference.

Associations between confounding variables and cognitive outcomes. All the cognitive scores increased with increasing SES and parental educational level $(p<0.001$ for all; data not shown). The cognitive performance of urban children was better than rural children in all the tests except verbal ability and attention and concentration ( $p<0.01$ for all). Scores for tests of visuospatial ability and fluid reasoning increased with increasing maternal age $(p<0.001$ for both). Children of multiparous mothers performed less well in tests of long-term storage and retrieval ability, planning and fluid reasoning, and verbal abilities ( $p<0.01$ for all) compared with primiparous children. Children examined in the morning $(n=465)$ performed better compared with those examined in the afternoon $(n=40 ; p$ for difference $=0.03)$. There were no associations of maternal BMI, height, and season of birth with cognitive outcomes.

Associations between birth measurements and cognitive outcomes. Multiple linear regression analyses describing the associations between birth measurements and cognitive performance are presented in Table 3 . The regression coefficient $(\beta)$ is the SD change in outcome per SD increase in birth measurements. Birthweight and head circumference were positively associated with learning ability/long-term storage and retrieval and visuospatial ability test scores, adjusted for the children's age, sex, and gestation (model 1 ). The associations were similar in boys and girls. These effects remained similar after adjusting for SLI and parental education (model 2) and on further adjustment for maternal age, BMI, height, parity, time of testing, and urban/rural residence (model 3). The associations were diminished after adjusting for the children's current head circumference (model 4). The associations did not change even after excluding children born to GDM mothers. There were no associations with the other cognitive measures. There were differences between the association of scores for learning ability/long-term storage and retrieval and the other cognitive tests in relation to head circumference at birth $[\beta=0.7$ (95\% CI: $0.20-1.26) ; p=0.007]$ and birthweight $[\beta=0.5$ (95\% CI: $-0.04-1.02) ; p=0.071]$ and, similarly, for the association of birthweight with verbal-ability scores $[\beta=$ 0.5 (95\% CI: -0.02 to $1.08 ; p=0.059$ ].

\section{DISCUSSION}

This is the first study from India examining associations between neonatal birth measurements and cognitive perfor- 
Table 2. Characteristics of the study cohort

\begin{tabular}{|c|c|c|c|}
\hline Birth measurements & $\begin{array}{c}\text { Boys }(n=239) \\
\text { Mean }(\mathrm{SD})\end{array}$ & $\begin{array}{c}\text { Girls }(n=266) \\
\text { Mean }(\mathrm{SD})\end{array}$ & $p^{*}$ \\
\hline Birthweight (kg) & $2.955(0.433)$ & $2.860(0.420)$ & 0.01 \\
\hline Head circumference $(\mathrm{cm})$ & $34.2(1.3)$ & $33.6(1.2)$ & $<0.0001$ \\
\hline Gestational age (wk) & $39.5(1.2)$ & $39.7(1.1)$ & 0.09 \\
\hline \multicolumn{4}{|c|}{ Measurements at the time of cognitive testing } \\
\hline Age $(y)$ & $9.7(0.3)$ & $9.7(0.3)$ & 0.7 \\
\hline Height (cm) & $131.4(5.5)$ & $130.4(5.9)$ & 0.057 \\
\hline BMI $\left(\mathrm{kg} / \mathrm{m}^{2}\right)$ & $14.6(1.7)$ & $14.7(2.0)$ & 0.6 \\
\hline Head circumference $(\mathrm{cm})$ & $50.8(1.4)$ & $50.5(1.5)$ & 0.064 \\
\hline \multicolumn{4}{|l|}{ Tests of cognitive function } \\
\hline Atlantis (score) & $67.6(17.9)$ & $68.2(16.8)$ & 0.7 \\
\hline Word order (score) & $16.2(2.6)$ & $16.7(2.5)$ & 0.02 \\
\hline Pattern reasoning (score) $\dagger$ & $9(4,13)$ & $11(6,14)$ & 0.004 \\
\hline \multicolumn{4}{|l|}{ Verbal fluency (score) } \\
\hline Test 1 -animals & $11.9(3.2)$ & $12.3(3.4)$ & 0.2 \\
\hline Test 2-first names & $14.8(4.1)$ & $17.5(5.2)$ & $<0.0001$ \\
\hline Kohs block design (score) $\dagger$ & $77.5(63.7-88.3)$ & $76.4(63.7-88.5)$ & 0.6 \\
\hline Coding-WISC-III (score) & $30.4(7.5)$ & $35.1(8.1)$ & $<0.0001$ \\
\hline \multicolumn{4}{|c|}{ Maternal characteristics at recruitment in pregnancy } \\
\hline Age $(y)$ & $23.9(4.2)$ & & \\
\hline \multicolumn{4}{|l|}{ Parity, $N(\%)$} \\
\hline 0 & $256(50.7)$ & & \\
\hline 1 & $170(33.7)$ & & \\
\hline 2 or more & $79(15.6)$ & & \\
\hline Height $(\mathrm{cm})$ & $154.3(5.3)$ & & \\
\hline BMI $\left(\mathrm{kg} / \mathrm{m}^{2}\right) \dagger$ & $23.2(21.0,26.0)$ & & \\
\hline \multicolumn{4}{|l|}{ Glucose tolerance test, $N(\%)$} \\
\hline Normal & $450(93.6)$ & & \\
\hline Abnormal & $31(6.4)$ & & \\
\hline \multicolumn{4}{|l|}{ Parent's current socioeconomic status } \\
\hline Standard of living index (score) & $36.5(8.2)$ & & \\
\hline \multicolumn{4}{|l|}{ Maternal education, $N(\%)$} \\
\hline$<10 \mathrm{y}$ of education & $177(35.1)$ & & \\
\hline $10 \mathrm{y}$ of education & $155(30.8)$ & & \\
\hline$>10 \mathrm{y}$ of education & $172(34.1)$ & & \\
\hline \multicolumn{4}{|l|}{ Paternal education, $N(\%)$} \\
\hline$<10 \mathrm{y}$ of education & $187(37.1)$ & & \\
\hline $10 \mathrm{y}$ of education & $199(39.5)$ & & \\
\hline$>10 \mathrm{y}$ of education & $118(23.4)$ & & \\
\hline \multicolumn{4}{|l|}{ Residence, $N(\%)$} \\
\hline Urban & $368(72.9)$ & & \\
\hline Rural & $137(27.1)$ & & \\
\hline
\end{tabular}

* $p$ value for the difference between boys and girls derived using $t$ test.

$\uparrow$ Transformed variable; values are median and interquartile range.

mance in 9- to 10-y-old healthy children born at full-term. We found that birthweight and head circumference at birth were positively associated with two tests of cognitive function measuring learning, long-term storage, and retrieval and visuospatial ability, after controlling for a range of potential confounders. The associations were reduced after adjusting for current $(9.5 \mathrm{y})$ head circumference, suggesting that cognitive performance may be influenced by prenatal environmental or genetic factors that determine both head size at birth and postnatal head growth.

Strengths of the study were that in a large sample of children, we had standardized anthropometric measurements at birth, a battery of cognitive function tests specifically adapted for, and validated in, a South Indian population, and collected data on a variety of potential confounding factors including gestational age, parity, parents' education, rural/ urban residence, SLI, and seasonality at birth. Unlike a number of earlier studies, which focused on low birthweight or preterm babies, our findings relate to healthy full-term babies. A limitation of the study was loss to follow-up (14\%), which could have introduced selection bias. However, birth measurements were similar in children who participated in the study and in those lost to follow-up. Another limitation was nonavailability of information about the children's current diet and other possible parental confounders such as maternal psychosocial stress or parents' intellectual ability. A hospitalbased study in India, where patients choose their healthcare facilities based on what they can afford, will not be representative of the whole population. The families visiting $\mathrm{HMH}$ would be representative of the "middle-class" section of society and would not include either the very poor or the very wealthy. 
Table 3. Associations between birth measurements and cognitive tests: multiple linear regression analysis

\begin{tabular}{|c|c|c|c|}
\hline \multirow[b]{2}{*}{ Birth measurements } & \multicolumn{3}{|c|}{ Cognitive tests } \\
\hline & $\begin{array}{l}\text { Atlantis (SD), } \\
\beta(95 \% \mathrm{CI})\end{array}$ & $\begin{array}{c}\text { Word order (SD), } \\
\beta(95 \% \mathrm{CI})\end{array}$ & $\begin{array}{c}\text { Pattern reasoning (SD), } \\
\beta(95 \% \mathrm{CI})\end{array}$ \\
\hline \multicolumn{4}{|l|}{ Birthweight (SD) } \\
\hline Model 1 & $0.1(0.03 \text { to } 0.22)^{* *}$ & $0.1(-0.03$ to 0.16$)$ & $0.1(-0.003$ to 0.18$)$ \\
\hline Model 2 & $0.1(-0.001$ to 0.18$)$ & $0.02(-0.07$ to 0.11$)$ & $0.03(-0.05$ to 0.12$)$ \\
\hline Model 3 & $0.1(0.02 \text { to } 0.21)^{*}$ & $0.03(-0.06$ to 0.13$)$ & $0.04(-0.05$ to 0.14$)$ \\
\hline Model 4 & $0.06(-0.04$ to 0.16$)$ & $-0.02(-0.12$ to 0.08$)$ & $0.005(-0.09$ to 0.10$)$ \\
\hline \multicolumn{4}{|l|}{ Head circumference (SD) } \\
\hline Model 1 & $0.2(0.07 \text { to } 0.26)^{* *}$ & $0.1(0.01 \text { to } 0.19)^{*}$ & $0.06(-0.04$ to 0.15$)$ \\
\hline Model 2 & $0.1(0.03 \text { to } 0.21)^{* *}$ & $0.05(-0.04$ to 0.15$)$ & $-0.01(-0.09$ to 0.08$)$ \\
\hline Model 3 & $0.1(0.04 \text { to } 0.23)^{* *}$ & $0.07(-0.02$ to 0.16$)$ & 0.001 ( -0.09 to 0.09$)$ \\
\hline Model 4 & $0.08(-0.02$ to 0.19$)$ & $0.004(-0.10$ to 0.11$)$ & $-0.06(-0.16$ to 0.04$)$ \\
\hline
\end{tabular}

Model 1 adjusted for sex, gestation, and child's age at the time of study; model 2 adjusted for model 1 parameters + SLI, parent's education; model 3 adjusted for model 2 parameters + parity, maternal age, BMI, height at pregnancy, urban/rural residence, and time of testing; and model 4 adjusted for model 3 parameters + child's current head circumference.

$* p \leq 0.05 ; * * \leq 0.01$.

The positive associations of birthweight and/or head circumference at birth with subsequent cognitive abilities are consistent with findings from several previous studies $(8-14)$, although some other studies found no associations $(33,34)$. In a Finnish cohort, among the various birth measurements, head circumference had the most robust association with tests of cognitive abilities (11). Our findings suggest that, even though brain growth is relatively protected in utero and tends to be the last organ to experience growth restriction (35), variations in fetal growth can be associated with variations in brain growth and development. Associations in our study between birth size and learning ability, long-term storage and retrieval, and visuospatial ability but not with other cognitive domains may indicate an impact of prenatal factors and/or a greater influence of postnatal environmental processes, such as parent's educational attainment, on some aspects of cognitive measures (36). The association with visuospatial ability in our study is in agreement with an earlier study (11). Our finding that some, but not all, aspects of cognitive function are related to birth size are also supported by the fact that the intercorrelations among the various cognitive tests used in our study were modest (ranging from 0.2 to 0.3 ), consistent with an earlier factor analysis of $\mathrm{KABC}$, suggestive of relative independence of various cognitive measures (37). Furthermore, in our study, there was some evidence of differences among the various cognitive tests in their association with birth size. These differential effects could indicate domain-specific effects; however, they could also have arisen from multiple statistical testing and/or low statistical power. Further research is needed, in this and other populations, to investigate the specificity of associations between size at birth and the different cognitive domains. While interpreting the clinical importance of our findings, it should be kept in mind that the effect size of the associations between head circumference at birth and later cognitive abilities were small.

Our findings are consistent with other studies in that the associations between birth measurements and cognitive performance were largely independent of socioenvironmental circumstances $(7,9,18,38)$, suggesting that they are not fully explained by socioeconomic confounding. Our findings that the associa- tions of birthweight and head circumference with cognitive abilities were reduced after adjusting for current head size is also consistent with findings from another study (10), suggesting that a common causal pathway links size at birth, postnatal head growth, and childhood cognitive function.

In conclusion, the factors associated with intellectual developments are highly complex and interrelated, but our results are consistent with the conclusion that prenatal head growth influences cognitive function, as measured at the age of 9-10 y. Head circumference has been used as a surrogate marker of brain volume in newborns and children (4) and has been used in previous studies that measured cognitive function (39), but a given head circumference is associated with a range of brain volumes because of age-dependent changes in the relationship between head circumference and brain volume (40). Although head circumference was an excellent predictor of brain volume in children up to $6 \mathrm{y}$ of age, the relationship was modest in older children and adults. In addition, the brain volume is considered an imperfect measure of functional capacity of the various regions of the brain (41). Nevertheless, studies on children with attention-deficit hyperkinetic disorder, a disorder with prominent cognitive dysfunction, have shown that such children have smaller brain volume compared with healthy controls (42). In older adults, people with larger head circumference may have reduced risks of cognitive decline (43). Although studies have shown that both genetic and environmental factors may impact maximal brain growth $(44,45)$, identification of critical early environmental influences may be important in optimizing an individual's genetic potential for intellectual abilities and, thus, on overall "capacity" in the population at large.

Acknowledgments. We thank the families who participated in the study and Dr BDR Paul (former Medical Director). We also thank the substantial contribution made to the study by Annamma, Baby, Devaki, Lalitha, Lalithakala, Savitha, Gopal Singh, Prathibha, Asha, Jayakumar, Saroja, Geetha, Chachyamma, Stephen, Nalinakshi, Rumana, Jane Pearce, and Patsy Coakley. 
Table 3. (Continued)

Cognitive tests

\begin{tabular}{|c|c|c|c|}
\hline $\begin{array}{l}\text { Verbal fluency animals } \\
\text { (SD), } \beta(95 \% \mathrm{CI})\end{array}$ & $\begin{array}{l}\text { Verbal fluencyfirst names } \\
\text { (SD), } \beta(95 \% \text { CI })\end{array}$ & $\begin{array}{l}\text { Kohs block design } \\
\text { (SD), } \beta(95 \% \text { CI })\end{array}$ & $\begin{array}{c}\text { Coding-WISC-III (SD), } \\
\beta(95 \% \mathrm{CI})\end{array}$ \\
\hline $0.04(-0.05$ to 0.13$)$ & $-0.01(-0.10$ to 0.08$)$ & $0.2(0.07 \text { to } 0.25)^{* *}$ & $0.03(-0.05$ to 0.12$)$ \\
\hline $0.01(-0.09$ to 0.10$)$ & $-0.04(-0.13$ to 0.05$)$ & $0.1(0.02 \text { to } 0.20)^{*}$ & $-0.005(-0.09$ to 0.08$)$ \\
\hline $0.03(-0.07$ to 0.13$)$ & $-0.05(-0.15$ to 0.05$)$ & $0.1(0.03 \text { to } 0.22)^{*}$ & $-0.04(-0.14$ to 0.05$)$ \\
\hline$-0.01(-0.11$ to 0.10$)$ & $-0.06(-0.16$ to 0.04$)$ & $0.09(-0.01$ to 0.19$)$ & $-0.07(-0.17$ to 0.02$)$ \\
\hline $0.02(-0.07$ to 0.12$)$ & $0.02(-0.08$ to 0.11$)$ & $0.1(0.04 \text { to } 0.23)^{* *}$ & $0.02(-0.07$ to 0.11$)$ \\
\hline$-0.02(-0.11$ to 0.08$)$ & $-0.02(-0.11$ to 0.07$)$ & $0.08(-0.01$ to 0.17$)$ & $-0.03(-0.12$ to 0.06$)$ \\
\hline$-0.01(-0.10$ to 0.09$)$ & $-0.01(-0.10$ to 0.09$)$ & $0.08(-0.01$ to 0.18$)$ & $-0.05(-0.14$ to 0.04$)$ \\
\hline$-0.06(-0.17$ to 0.04$)$ & $-0.05(-0.15$ to 0.06$)$ & $0.04(-0.06$ to 0.14$)$ & $-0.12(-0.22 \text { to }-0.02)^{*}$ \\
\hline
\end{tabular}

\begin{tabular}{|c|c|c|c|}
\hline $\begin{array}{l}\text { Verbal fluency animals } \\
\text { (SD), } \beta(95 \% \mathrm{CI})\end{array}$ & $\begin{array}{l}\text { Verbal fluencyfirst names } \\
\quad \text { (SD), } \beta \text { (95\% CI) }\end{array}$ & $\begin{array}{l}\text { Kohs block design } \\
(\mathrm{SD}), \beta(95 \% \mathrm{CI})\end{array}$ & $\begin{array}{c}\text { Coding-WISC-III (SD), } \\
\beta(95 \% \mathrm{CI})\end{array}$ \\
\hline $0.04(-0.05$ to 0.13$)$ & $-0.01(-0.10$ to 0.08$)$ & $0.2(0.07 \text { to } 0.25)^{* *}$ & $0.03(-0.05$ to 0.12$)$ \\
\hline $0.01(-0.09$ to 0.10$)$ & $-0.04(-0.13$ to 0.05$)$ & $0.1(0.02 \text { to } 0.20)^{*}$ & $-0.005(-0.09$ to 0.08$)$ \\
\hline $0.03(-0.07$ to 0.13$)$ & $-0.05(-0.15$ to 0.05$)$ & $0.1(0.03 \text { to } 0.22)^{*}$ & $-0.04(-0.14$ to 0.05$)$ \\
\hline$-0.01(-0.11$ to 0.10$)$ & $-0.06(-0.16$ to 0.04$)$ & $0.09(-0.01$ to 0.19$)$ & $-0.07(-0.17$ to 0.02$)$ \\
\hline $0.02(-0.07$ to 0.12$)$ & $0.02(-0.08$ to 0.11$)$ & $0.1(0.04 \text { to } 0.23)^{* *}$ & $0.02(-0.07$ to 0.11$)$ \\
\hline$-0.02(-0.11$ to 0.08$)$ & $-0.02(-0.11$ to 0.07$)$ & $0.08(-0.01$ to 0.17$)$ & $-0.03(-0.12$ to 0.06$)$ \\
\hline$-0.01(-0.10$ to 0.09$)$ & $-0.01(-0.10$ to 0.09$)$ & $0.08(-0.01$ to 0.18$)$ & $-0.05(-0.14$ to 0.04$)$ \\
\hline$-0.06(-0.17$ to 0.04$)$ & $-0.05(-0.15$ to 0.06$)$ & $0.04(-0.06$ to 0.14$)$ & $-0.12(-0.22 \text { to }-0.02)^{*}$ \\
\hline
\end{tabular}

Coding-WISC-III (SD), $\beta(95 \% \mathrm{CI})$

\section{REFERENCES}

1. Victora CG, Adair L, Fall C, Hallal PC, Martorell R, Richter L, Sachdev HS Maternal and Child Undernutrition Study Group 2008 Maternal and child undernutrition: consequences for adult health and human capital. Lancet 371:340-357

2. Tanner JM 1990 Fetus Into Man: Physical Growth From Conception to Maturity. Harvard University Press, Cambridge

3. Webb SJ, Monk CS, Nelson CA 2001 Mechanisms of postnatal neurobiological development: implications for human development. Dev Neuropsychol 19:147-171

4. Cooke RW, Lucas A, Yudkin PL, Pryse-Davies J 1977 Head circumference as an index of brain weight in the fetus and newborn. Early Hum Dev 1:145-149

5. Hack M, Klein NK, Taylor HG 1995 Long-term developmental outcomes of low birth weight infants. Future Child 5:176-196

6. Bhutta AT, Cleves MA, Casey PH, Cradock MM, Anand KJ 2002 Cognitive and Behavioural Outcomes of School-Aged Children Who Were Born Preterm: a meta-analysis. JAMA 288:728-737

7. Shenkin SD, Starr JM, Deary IJ 2004 Birth weight and cognitive ability in childhood: a systematic review. Psychol Bull 130:989-1013

8. Brennan TL, Funk SG, Frothingham TE 1985 Disproportionate intra-uterine head growth and developmental outcome. Dev Med Child Neurol 27:746-750

9. Richards M, Hardy R, Kuh D, Wadsworth ME 2001 Birth weight and cognitive function in the British 1946 birth cohort: longitudinal population based study. BMJ 322:199-203

10. Gale CR, O'Callaghan FJ, Bredow M, Martyn CN 2006 The influence of head growth in fetal life, infancy, and childhood on intelligence at the ages of 4 and 8 years. Pediatrics 118:1486-1492

11. Heinonen K, Räikkönen K, Pesonen AK, Kajantie E, Andersson S, Eriksson JG, Niemelä A, Vartia T, Peltola J, Lano A 2008 Prenatal and postnatal growth and cognitive abilities at 56 months of age: a longitudinal study of infants born at term. Pediatrics 121:e1325-e1333

12. Silva A, Metha Z, O'Callaghan FJ 2006 The relative effect of size at birth, postnatal growth and social factors on cognitive function in late childhood. Ann Epidemiol 16:469-476

13. Tong S, Baghurst P, McMichael A 2006 Birthweight and cognitive development during childhood. J Paediatr Child Health 42:98-103

14. Broekman BF, Chan YH, Chong YS, Quek SC, Fung D, Low YL, Ooi YP, Gluckman PD, Meaney MJ, Wong TY, Saw SM 2009 The influence of birth size on intelligence in healthy children. Pediatrics 123:e1011-e1016

15. Grantham-McGregor SM, Lira PI, Ashworth A, Morris SS, Assuncao AM 1998 The development of low birth weight term infants and the effects of the environment in northeast Brazil. J Pediatr 132:661-666

16. Villar J, Smeriglio V, Martorell R, Brown CH, Klein RE 1984 Heterogeneous growth and mental development of intrauterine growth-retarded infants during the first 3 years of life. Pediatrics 74:783-791

17. Chaudhari S, Otiv M, Chitale A, Pandit A, Hoge M 2004 Pune low birth weight study-cognitive abilities and educational performance at twelve years. Indian Pediatr 41:121-128

18. Yajnik CS, Fall CH, Coyaji KJ, Hirve SS, Rao S, Barker DJ, Joglekar C, Kellingray S 2003 Neonatal anthropometry: the thin-fat Indian baby. The Pune Maternal Nutrition Study. Int J Obes Relat Metab Disord 27:173-180

19. Krishnaveni GV, Hill JC, Veena SR, Leary SD, Saperia J, Chachyamma KJ, Karat SC, Fall CH 2005 Truncal adiposity is present at birth and in early childhood in South Indian children. Indian Pediatr 42:527-538

20. Sachdev HP 1997 Low birth weight in South Asia. In: Gillespie SR (eds) Malnutrition in South Asia: A Regional Profile. UNICEF, ROSA, Kathmandu, pp 23-50

21. Richards M, Hardy R, Kuh D, Wadsworth ME 2002 Birthweight, postnatal growth and cognitive function in a national UK birth cohort. Int J Epidemiol 31:342-348

22. Hill JC, Krishnaveni GV, Annamma I, Leary SD, Fall CH 2005 Glucose tolerance in pregnancy in South India: relationships to neonatal anthropometry. Acta Obstet Gynecol Scand 84:159-165
23. Carroll JB 1993 Human Cognitive Abilities: A Survey of Factor-Analytic Studies Cambridge University Press, New York, pp 143-440

24. Kaufman AS, Kaufman NL 2004 Kaufman Assessment Battery for Children. 2nd ed. Manual. Pearson, San Antonio

25. Korkman M, Kemp SL, Kirk U 2001 Effects of age on neurocognitive measures of children ages 5 to 12 : a cross-sectional study on 800 children from the United States. Dev Neuropsychol 20:331-354

26. Kohs SC 1923 Intelligence Measurement: A Psychological and Statistical Study Based Upon the Block-Design Tests. Macmillan, Oxford, UK

27. Wigg CM, Duro LA 1999 The Koh's block tests as an important instrument to investigate the visuo-spatial impairments in myotonic dystrophy. Part I. Quantitative and qualitative analysis. Arq Neuropsiquiatr 57:547-555

28. Wechsler D 1991 Manual for the Wechsler Intelligence Scale for Children. 3rd ed Psychological Corporation, San Antonio

29. Malda M, van de Vijver FJ, Srinivasan K, Transler C, Sukumar P, Rao K 2008 Adapting a cognitive test for a different cultures: an illustration of qualitative procedures. Psychol Sci 50:451-468

30. Malda M, van de Vijver FJ, Srinivasan K, Transler C, Sukumar P Traveling with cognitive tests: testing the validity of a KABC-II adaptation in India. Assessment 2009. [Epub ahead of print.]

31. International Institute for Population Sciences (IIPS) and Operations Research Centre (ORC) Macro 2001 National Family Health Survey (NFHS-2), India $1998-$ 1999. Karnataka, Mumbai: IIPS pp 24-31

32. Cole TJ, Green PJ 1992 Smoothing reference centile curves: the LMS method and penalized likelihood. Stat Med 11:1305-1319

33. Martyn CN, Gale CR, Sayer AA, Fall C 1996 Growth in utero and cognitive function in adult life: follow up study of people born between 1920 and 1943. BMJ 312:1393-1396

34. Sorensen HT, Sabroe S, Olsen J, Rothman KJ, Gillman MW, Fischer P 1997 Birth weight and cognitive function in young adult life: historical cohort study. BMJ 315:401-403

35. Yajnik CS 2004 Obesity epidemic in India: intrauterine origins? Proc Nutr Soc 63:387-396

36. Klenberg L, Korkman M, Lahti-Nuuttila P 2001 Differential development of attention and executive functions in 3-to-12 year old Finnish children. Dev Neuropsychol 20:407-428

37. Valencia RR, Rankin RJ 1986 Factor analysis of the K-ABC for groups of Anglo and Mexican American children. J Educ Meas 23:209-219

38. Lawlor DA, Bor W, O'Callaghan MJ, Williams GM, Najman JM 2005 Intrauterine growth and intelligence within sibling pairs: findings from the Mater-University study of pregnancy and its outcomes. J Epidemiol Community Health 59:279-282

39. Vernon PA, Wickett JC, Bazana PG, Stelmark RM 2000 The neuropsychology and psychophysiology of human intelligence. In: Sternberg RJ (ed) Handbook of Intelligence. Cambridge University Press, Cambridge, pp 245-264

40. Bartholomeusz HH, Courchesne E, Karns CM 2002 Relationship between head circumference and brain volume in healthy normal toddlers, children and adults. Neuropediatrics 33:239-241

41. Drachman DA 2002 Hat size, brain size, intelligence and dementia: what morphometry can tell us about brain function and disease? Neurology 59:156-157

42. Castellanos FX, Lee PP, Sharp W, Jeffries NO, Greenstein DK, Clasen LS, Blumenthal JD, James RS, Ebens CL, Walter JM, Zijdenbos A, Evans AC, Gledd JN, Rapoport JL 2002 Developmental trajectories of brain volume abnormalities in children and adolescents with attention-deficit/hyperactivity disorder. JAMA 288:1740-1748

43. Gale CR, Walton S, Martyn CN 2003 Foetal and postnatal head growth and risk of cognitive decline in old age. Brain 126:2273-2278

44. Toga AW, Thompson PM 2005 Genetics of brain structure and intelligence. Annu Rev Neurosci 28:1-23

45. Gale CR, O'Callaghan FJ, Godfrey KM, Law CM, Martyn CN 2004 Critical periods of brain growth and cognitive function in children. Brain 127:321-329 